\title{
Treatment of Nasolacrimal Duct Obstruction in Infants by Probing Without Irrigation
}

\author{
Esmat Karbasi $^{1}$, Narges Khanjani ${ }^{2}$ \\ ${ }^{1}$ Department of Ophthalmology, School of Medicine, Kerman University of Medical Sciences, Kerman, Iran \\ ${ }^{2}$ Neurology Research Center, Kerman University of Medical Sciences, Kerman, Iran
}

Email address:

n_khanjani@kmu.ac.ir (N. Khanjani)

\section{To cite this article:}

Esmat Karbasi, Narges Khanjani. Treatment of Nasolacrimal Duct Obstruction in Infants by Probing Without Irrigation. Science Journal of Clinical Medicine. Vol. 8, No. 2, 2019, pp. 13-16. doi: 10.11648/j.sjcm.20190802.12

Received: April 15, 2019; Accepted: May 29, 2019; Published: June 19, 2019

\begin{abstract}
Nasolacrimal duct obstruction (NLDO) is a common congenital abnormality. Some obstructions resolve spontaneously and some require probing surgery with irrigation. However, the necessity of irrigation after probing is still under doubt. The study included 131 eyes (114 children) with persistent NLDO, between 9 to 48 months of age with no previous nasolacrimal surgical procedures, who had attended the ophthalmology clinic at Shafa Hospital, Kerman, Iran for NLDO treatment. Probing was done through the superior or inferior canalicular system into the nasolacrimal canal, not succeeded by irrigation. The duration of anesthesia was shorter than usual. Subjects were visited at 1 and 6 months after surgery. Before the surgery, all of the eyes had epiphora, $56 \%$ had mucopurolent discharge and $18 \%$ had a history of dacrocystitis, in which after the surgery the prevalence dropped to $6 \%, 5 \%$ and $4 \%$. The average procedure time under general anesthesia was 5.9 minutes and the average recovery time wan 7.2 minutes, which was shorter than surgery with irrigation. In this study, we experienced similar results of probing without irrigation in comparison to probing with irrigation, also the surgery and anesthesia duration was shorter and the risk of aspiration was little. More studies from other centers and larger populations especially RCTs should be performed to confirm our results.
\end{abstract}

Keywords: Nasolacrimal Duct Obstruction, Treatment, Probing, Irrigation

\section{Introduction}

Congenital nasolacrimal duct obstruction is a common congenital abnormality present in 5 to $30 \%$ of newborns [13 ], but clinically evident in only 2 to $6 \%$ of full term infants [3]. Most of these obstructions open without treatment within 4 to 6 weeks after birth, and in 50 to $90 \%$ open during the first 6 to 12 months of life. Therefore a number of studies support medical and conservative management with topical antibiotics and nasolacrimal sac/duct massage up until 12 to 13 months $[3,4]$.

Nasolacrimal duct probing in infancy and early childhood using general or topical anesthesia or IV sedation [4] is an apparently successful treatment of congenital nasolacrimal duct obstruction (NLDO), however the proper time is under debate [1-5]. Studies of probing up to 6 months of age indicated a success rate of $79-98 \%$ compared to a natural resolution rate of $76-100 \%$ [3]. Some researchers believe that the rate of success after probing falls with increases in child's age and the earlier the probing, the greater the success rate [6-8], also persistent obstruction leads to recurrent inflammation, infection and scarring which can cause persistent lacrimal symptoms [3].

However, many articles do not show difference in success rates of probing at different ages [9-11] and some studies think the success of probing is determined more by the nature or complexity of the obstruction than by the age of the patient $[3,12]$. Also advocates of later probing discuss the fact that there is a high degree of spontaneous resolution [3].

Probing with irrigation of the duct often imposes the risk of aspiration especially if general anesthesia is done without intubation. We recently conducted a study of treating nasolacrimal duct obstruction by probing and without irrigation, what we call simple probing. There has been few trials focusing on probing without irrigation for congenital nasolacrimal duct obstruction. One retrospective study has reported that probing without irrigation for NLDO after 1 
year of age was successful and had similar efficacy compared to traditional probing with irrigation [13].

In this study, we aimed to compare the outcome of simple probing (probing without irrigation) and traditional probing (with irrigation) in children between 6 to 48 months of age in order to suggest the possibility of eliminating irrigation; which will lead to a lower aspiration risk, shorter duration of anesthesia and quicker recovery.

\section{Methods}

This hospital based study was approved by the Ethics Committee of Kerman University of Medical Sciences (Ethics Code: IR. KMU. REC.1394.222) and was conducted at the Ophthalmology Department of Shafa Hospital, Kerman, Iran from 2008 until 2017.

The study included 243 eyes ( 214 children) with persistent NLDO, between 9 to 48 months of age with no previous nasolacrimal surgical procedures, who had attended the ophthalmology clinic at this hospital for NLDO treatment. The main eligibility criteria were epiphora, increased tear meniscus with or without obvious mucopurulent discharge. The fluorescein dye disappearance test was used to confirm the diagnosis [4, 14]. None of the children had upper respiratory tract infection or ocular surface irritation. An informed written consent was taken from the parents of the children before carrying out the procedure.

Children were allocated to two groups. In one group (100 children, 112 eyes) traditional probing (with irrigation) and in the other group (114 children, 131 eyes) simple probing (without irrigation) was conducted.

All children did not eat or drink from 2 hours before the procedure. Procedures were performed under general anesthesia with halothane and $\mathrm{N}_{2} \mathrm{O}$ in the hospital outpatient surgical department without an IV line. Oxygen was given by nasal cannula while oxygen saturation was monitored with pulse oximetry.

Probing consisted of dilation of the superior or inferior punctum using a punctum dilator and the passage of a 00 bowman probe through the superior or inferior canalicular system into the nasolacrimal canal.

In the simple probing group, no irrigation was performed afterwards; and because irrigation after probing was not done, the anesthesia duration was shorter than usual and lasted only about 5 minutes. Topical antibiotics were prescribed afterwards.

All probing (with and without irrigation) were done by one surgeon (the first author of this study).

All subjects had follow-up visits timed 1 month and 6 months after surgery. At both visits parents were questioned regarding the presence of symptoms and the surgeon evaluated presence or absence of epiphora, discharge and swelling in the area of the lacrimal sac. Some patients did not show up for follow-up visits and the presence of symptoms were asked from the parents through phone calls.

The probing success was defined as complete remission of symptoms within 1 month of the procedure that continued until 6 months.

The symptoms were compared before and after surgery in each group separately by the McNemar's test. Also, the remission rates were compared between the two groups and Relative Risks $(95 \% \mathrm{CI})$ were calculated. Children were also analyzed in two age subgroups, 9-15 months and 16 to 48 months.

\section{Result}

The results of the comparison between symptoms before and after probing in each group has been shown in Table 1.

Table 1. Prevalence of symptoms before and 6 months after probing in each group.

\begin{tabular}{|c|c|c|c|c|c|c|c|}
\hline & & Epiphora & p-value & MP Discharge & p-value & Dacrocystitis & p-value \\
\hline \multirow{8}{*}{$\begin{array}{l}\text { Probing } \\
\text { without } \\
\text { irrigation }\end{array}$} & 9-15 months (68 eyes) & & \multirow{4}{*}{$<0.001$} & & \multirow{4}{*}{$<0.001$} & & \multirow{4}{*}{$<0.001$} \\
\hline & Pre-operative & $68(100 \%)$ & & $43(63 \%)$ & & $14(20 \%)$ & \\
\hline & Post-operative & $4(5.8 \%)$ & & $2(2.9 \%)$ & & $0(0 \%)$ & \\
\hline & $16-48$ months ( 63 eyes) & & & & & & \\
\hline & Pre-operative & $63(100 \%)$ & \multirow{3}{*}{$<0.001$} & $30(47 \%)$ & \multirow{3}{*}{$<0.001$} & $10(16 \%)$ & \multirow{3}{*}{0.004} \\
\hline & Post-operative & $4(6.3 \%)$ & & $2(3.1 \%)$ & & $1(1.5 \%)$ & \\
\hline & Total (131 eyes) & & & & & & \\
\hline & $\begin{array}{l}\text { Post-operative } \\
\text { Please add a space here } \\
9-15 \text { months ( } 63 \text { eyes) }\end{array}$ & $8(6.1 \%)$ & $<0.001$ & $4(3.0 \%)$ & $<0.001$ & $1(0.7 \%)$ & $<0.001$ \\
\hline \multirow{6}{*}{$\begin{array}{l}\text { Probing with } \\
\text { irrigation }\end{array}$} & Pre-operative & $63(100 \%)$ & \multirow{2}{*}{$<0.001$} & $47(74.6 \%)$ & \multirow{2}{*}{$<0.001$} & $8(12.7 \%)$ & \multirow{2}{*}{0.013} \\
\hline & Post-operative & $7(11.1 \%)$ & & $4(6.3 \%)$ & & $1(1.6 \%)$ & \\
\hline & $\begin{array}{l}\text { 16-48 months ( } 49 \text { eyes) } \\
\text { Pre-operative }\end{array}$ & $49(100 \%)$ & \multirow[b]{2}{*}{$<0.001$} & & \multirow[b]{2}{*}{$<0.001$} & & \multirow[b]{2}{*}{0.002} \\
\hline & $\begin{array}{l}\text { Pre-operative } \\
\text { Post-operative }\end{array}$ & $5(10.2 \%)$ & & $\begin{array}{l}43(87.7 \%) \\
2(4.1 \%)\end{array}$ & & $\begin{array}{l}11(22.4 \%) \\
1(2.0 \%)\end{array}$ & \\
\hline & Pre-operative & $112(100 \%)$ & \multirow{2}{*}{$<0.001$} & $90(80.3 \%)$ & \multirow{2}{*}{$<0.001$} & $19(16.7 \%)$ & \multirow{2}{*}{$<0.001$} \\
\hline & Post-operative & $12(10.7 \%)$ & & $6(5.3 \%)$ & & $2(1.8 \%)$ & \\
\hline
\end{tabular}

All of the eyes had epiphora, more than half had mucopurulent discharge and some had a history of dacryocystitis. All symptoms resolved significantly in both groups and all age subgroups. 
For the patients who had probing with irrigation, the time of general anesthesia was longer than the group without irrigation. The duration of surgery in the group with without irrigation was also shorter (about 3 minutes) in comparison to the group with irrigation (about 5 minutes).

Laryngospasm happened in two patients of the control group (with irrigation) but the other children recovered quickly after surgery. No surgical complications were reported for any of the patients after the follow-up period of 6 months.

The relative risk of comparison between the two groups in total and in age subgroups have been shown in table 2. Most RRs are less than 1 showing less symptoms in the probing without irrigation group. However, all RRs were insignificant.

Table 2. Relative Risk of symptoms after surgery and the p-value of comparison.

\begin{tabular}{|c|c|c|c|c|c|c|c|}
\hline & & Epiphora & $\begin{array}{l}\text { RR }(95 \% \text { CI }) \\
\text { p-value }\end{array}$ & $\begin{array}{l}\text { MP } \\
\text { Discharge }\end{array}$ & $\begin{array}{l}\text { RR }(95 \% \text { CI }) \\
\text { p-value }\end{array}$ & Dacrocystitis & $\begin{array}{l}\text { RR }(95 \% \text { CI }) \\
\text { p-value }\end{array}$ \\
\hline $9-15$ & Probing w/o irrigation & $4 / 68(5.8 \%)$ & $0.52(0.16-1.72)$ & $2 / 43(4.6 \%)$ & $0.57(0.11-2.95)$ & $0 / 14(0.0 \%)$ & $0.22(0.01-4.92)$ \\
\hline months & Probing + irrigation & $7 / 63(11.1 \%)$ & 0.29 & $4 / 47(8.5 \%)$ & 0.50 & $1 / 8(12.5 \%)$ & 0.34 \\
\hline months & Probing + irrigation & $5 / 49(10.2 \%)$ & 0.49 & $2 / 43(4.6 \%)$ & 0.73 & $1 / 11(9.1 \%)$ & 0.95 \\
\hline \multirow{2}{*}{ Total } & Probing w/o irrigation & $8 / 131(6.1 \%)$ & $0.59(0.25-1.41)$ & $4 / 73(5.4 \%)$ & $0.83(0.24-2.84)$ & $1 / 24(4.2 \%)$ & $0.42(0.04-4.31)$ \\
\hline & Probing + irrigation & $12 / 112(10.7 \%)$ & 0.24 & $6 / 90(6.6 \%)$ & 0.77 & $2 / 19(10.5 \%)$ & 0.46 \\
\hline
\end{tabular}

\section{Discussion}

Probing of the nasolacrimal system is a standard therapeutic procedure in the management of congenital NLDO [3]. In this study, we compared probing without irrigation with traditional probing (with irrigation) and showed that probing without irrigation is as effective as probing without irrigation, suggesting that the routine irrigation after probing is unnecessary.

Our success rates are similar to other studies in which probing with irrigation were done. In these studies success rates from 84 to $95.5 \%$ were reported [4, 14]. Nasolacrimal intubation for the primary treatment of congenital NLDO was successful in $91 \%$ of the children 6 to 45 months of age in another study [15].

Probing with irrigation under general anesthesia can increase the risk of aspiration. In one study, irrigation of the nasolacrimal duct was avoided to decrease the risk of laryngospasm [4]. In our study two cases of laryngospasm were reported in the group with irrigation as well.

A significant benefit of probing under general anesthesia without an IV line is the less time spent in the operating rooms for the procedure. Also, prolonged anesthesia can increase morbidity. Many studies have suggested the use of anesthesia techniques other than general anesthesia in order to reduce the length of sedation [1-4]. In this study by eliminating the irrigation step the length of general anesthesia was shortened. Also, administering an IV line for children that can be difficult to perform and time consuming, was not needed.

Based on our study it can be proposed that if surgeons have enough experience and know the exact path of the lacrimal drainage system, successful probing can be done, and afterward irrigation is not necessary and does not further increase the success rate, but only helps surgeons confirm the patency of the lacrimal system.

It is important to understand that the irrigation fluid force is much more than tear force, therefore a patent lacrimal duct through the force of irrigation may not perform well during natural circumstances. In fact, in functional and partial obstruction the irrigation fluid can pass throw the nasolacrimal duct, but the patient still has epiphora afterwards.

In this study, we experienced a good result in probing without irrigation, also the surgical and anesthesia duration was shorter and the risk of aspiration was little. More studies from other centers and larger populations, especially RCTs should be performed to confirm our results.

\section{Conclusion}

Probing without irrigation has similar results to probing with irrigation in the treatment of Nasolacrimal Duct Obstruction in Infants. Also, the surgery and anesthesia duration is shorter and the risk of aspiration is less. However, more studies on larger populations should be performed to confirm our results.

\section{References}

[1] Lala-Gitteau E, Majzoub S, Pisella PJ. Utilisation du melange protoxyde d'azote-oxygene lors du sondage des voies lacrymales chez l'enfant. J Fr Ophtalmol. 2007; 30(9): 924-7.

[2] Karabas LV, Elibol O, Yuksel N, Gurkan Y, Altintas O, Caglar Y. Probing for nasolacrimal duct obstruction using intranasal midazolam sedation as an alternative to general anesthesia. $\mathrm{J}$ Pediatr Ophthalmol Strabismus. 2006; 43: 79-84.

[3] Shrestha JB, Bajimaya S, Hennig A, Shankar K. Outcome of probing under topical anesthesia in children below 18 months of age with congenital nasolacrimal duct obstruction. The internet journal of Ophthalmology and Visual Science. 2009; $7(1)$.

[4] Movaghar M, Kodsi S, Merola C, Doyle J. Probing for nasolacrimal duct obstruction with intravenous propofol sedation. Journal of AAPOS. 2000; 4: 179-82.

[5] Suresh S, Park J. Nasolacrimal duct probing in infants and children: an easy technique for administering general anesthesia. Anesth Analg. 2003; 97: 1852-8. 
[6] Paul TO, Shephard R. Congenital nasolacrimal duct obstruction: natural history and the timing of optimal intervention. J Pediatr Ophthalmol Strabismus. 1994; 31: 3627.

[7] Arora S, Koushan K, Harvey JT. Success rates of primary probing for congenital nasolacrimal obstruction in children. J AAPOS 2012; 16: 173-6.

[8] Hung CH, Chen YC, Lin SL, Chen WL. Nasolacrimal Duct Probing under Topical Anesthesia for Congenital Nasolacrimal Duct Obstruction in Taiwan. Pediatr Neonatol. 2015; 56(6): 402-7

[9] Young JDH, MacEwen CJ, Oqston SA. Congenital nasolacrimal duct obstruction in the second year of life: a multicenter trial of management. Eye. 1996; 10: 485-91.

[10] Honavar S, Vasudha EP, Rao GN. Outcome of probing for congenital nasolacrimal duct obstruction in older children. Amer J Ophtalmol. 2000; 130: 42-8.

[11] Lee KA, Chandler DL, Repka MX, Melia M, Beck RW,
Summers CG, et al. A Comparison of Treatment Approaches for Bilateral Congenital Nasolacrimal Duct Obstruction. Am J Ophthalmol. 2013; 156: 1045-50.

[12] Medghalchi A, Mohammadi MJ, Soltani Moghadam R, Dalili H. Results of Nasolacrimal Duct Probing in Children between 9-48 Months. Acta Medica Iranica. 2014; 52(7): 545-51.

[13] Isaza G, Arora S. Probing without Irrigation in Children with Congenital Nasolacrimal Duct Obstruction. Clin Invest Med. 2013; 36(3): E158-E62.

[14] Cakmak S, Yildirim M, Sakalar Y, Keklikci U, Alakus F. Is it necessary to accompany probing with endoscopy in cases of congenital nasolacrimal canal obstruction?. Int $\mathrm{J}$ Pediatr Otorhinolaryngol. 2010; 74(9): 1013-5.

[15] Pediatric Eye Disease Investigator Group, Repka MX, Melia BM, Beck RW, Atkinson CS, Chandler DL, et al. Primary treatment of nasolacrimal duct obstruction with nasolacrimal duct intubation in children younger than 4 years of age. Journal of AAPOS. 2008; 12(5): 445-50. 